\title{
Finite-state recall revealed by backward learning curves constructed from confidence ratings
}

\author{
ANTHONY F. JORM and JOHN D. BAIN \\ University of Queensland, Brisbane, Australia 4067
}

\begin{abstract}
Two experiments were carried out to show that the constancy of Type II $\mathrm{d}^{\prime}$ in recall is not an artifact, but is due to finite-state processes as suggested by Bernbach (1967). The following conclusions were reached: (1) The constancy of Type II $\mathrm{d}^{\prime}$ is not an artifact due to the inclusion of intralist intrusions in the class of incorrect responses; (2) backward learning curves constructed from confidence ratings gave clear evidence of all-or-none recall; (3) recall appeared to be all or none whether the subjects learned by rote or with a mnemonic; (4) the discriminability index derived from Luce's (1959) choice theory did not exhibit constancy over trials, unlike Type II $d^{\prime}$ and despite the fact that backward rating curves indicated all-or-none processes.
\end{abstract}

Murdock (1966) applied signal detection theory (SDT) to associative recall in an attempt to isolate the contribution of criterion placement to the serial position effect, on the hypothesis that subjects are more willing to give responses at the end of a list than at the beginning. He forced subjects to give a response for each serial position and had them rate how confident they were that each response was correct. Murdock found that the resulting Type II d' remained relatively constant over serial positions, while $\beta$ and correct responses varied as a function of serial position. However, as Banks (1970) has noted, $\beta$ in this context cannot be interpreted as an overt response criterion, since the latter was made negligible through forced responding. Furthermore, forced responding did not reduce the serial position effect for correct responses. Instead, overt errors replaced omissions.

Bernbach $(1967,1971$ a) has argued that the criterion in the question is that above which some particular confidence rating will be made. His model assumes a a two-state memory trace plus a continuous rating axis of apparent oldness that results from imperfection in the process of matching presented (or recalled) items to those tagged in memory. Remembered and unlearned items are differentially distributed on this axis with a mean difference of $d^{*}$. Recognition memory operating characteristics (MOCs) constructed from confidence ratings are hypothesized to reflect this average discriminability of unlearned and remembered items multiplied by the proportion of target items in the remembered state $(1-\delta)$ so that, with perfect retention, rating MOCs in recognition reflect $d^{*}$ alone. For recall, on the other hand, rating MOCs are assumed

Anthony F. Jorm is now at Deakin University, Geelong, Australia. Requests for reprints should be sent to John D. Bain, Department of Psychology, University of Queensland, St. Lucia, Brisbane, Australia 4067 to simulate the perfect retention case in recognition whatever the actual rate of forgetting since, except for guessing, rated items are either correct recalls and thus in the remembered state or errors and thus in the unlearned state. Bernbach therefore predicts that Type II $\mathrm{d}^{\prime}$ derived from rating MOCs in recall (corrected for guessing where appropriate) will remain constant across those conditions that influence the distribution of items in the unlearned and remembered states, such as the recency effect for correct associative recall found by Murdock (1966).

In contrast, Banks (1970) has argued that Murdock's (1966) results are an artifact of forced responding and cannot be taken as support for Bernbach's (1967) model. Banks claims that subjects recall what they can and give these responses high ratings, then guess and give the guesses low ratings. Hit and correct rejection rates are therefore complementary and Type II $\mathrm{d}^{\prime}$ remains relatively constant despite changes in retention. According to this account, subjects fail to discriminate between degrees of learning, not because such differences are absent, but because they are small in contrast to the low confidence associated with guesses. If this is correct, other measures sensitive to continuous memory information should manifest a change, while Type II d' does not.

Banks (1971) has advanced another important argument against the validity of Murdock's (1966) findings. His suggestion is that, as the strength of the correct responses increases, there could be a proportionate increase in the strength of incorrect responses. On the assumption that a Type II analysis reflects a subject's ability to discriminate his intrusions from his correct responses, $\mathrm{d}^{\prime}$ could remain invariant despite changes in absolute response strength. Although this outcome is contrary to the results that Bernbach (1971b) obtained with simulations of continuous strength models, the inconsistency is probably due to 
Bernbach's assumption of independence of correct and incorrect responses.

A different account of Murdock's (1966) results has been offered by Ingleby (1968, p. 259). He assumed recall to be a multialternative forced-choice recognition task with a large set of alternatives. By analogy with Clarke's (1960) research on speech perception, Ingleby proposed that a constant Type II $\mathrm{d}^{\prime}$ in recall reflects the finding that variations in signal-to-noise ratio have a diminishing effect on Type II $d^{\prime}$ as the number of alternatives increases. However, this argument seems dubious both because of the questionable analogy drawn between speech perception and recall, and because of doubts about the comparability of recognition and recall processes. Although early theorists favored an interpretation of recall as a covert multialternative recognition task (Lecocq \& Tiberghien, 1973), recent controversy even goes so far as to doubt the covert evaluation of any alternatives during recall (Tulving, 1976). Assuming the answer to lie somewhere between these extremes (Anderson \& Bower, 1974; Brown, 1976; Kintsch, 1974) considerably reduces the plausibility of Ingleby's explanation.

There remains a clear controversy, however, between Banks (1971) and Bernbach (1971a) over the implications to be drawn from Type II SDT analyses of recall data: Do they, or do they not, reflect finitestate memory information? This controversy is the main focus of the present research. Because it was clear from Banks' arguments that a SDT analysis alone is ambiguous, the present experiments were designed so that an additional corroborative analysis could be made. That chosen was the backward learning curve (Suppes \& Ginsberg, 1963), a particularly appropriate version of which has been used by Teghtsoonian and Teghtsoonian (1972). They constructed backward leaming curves using confidence ratings as the index of memory strength in recognition experiments, and their results favored a finite-state model. Since confidence ratings are an integral part of the Type II SDT procedure, the Teghtsoonian method provides an alternative use of the one set of data.

Aspects of the procedure may be at variance with the full Bernbach (1967) model, however, since, as a remembering rather than a learning model, it assumes that each item enters the learned state immediately after its presentation, and with probability $\delta$ it returns to the unlearned state before test. The reverse of these transitions would be required to describe typical twostate learning. Moreover, by directly equating the proportion of items in the unlearned state with $\delta$, Bernbach predicts that the probability of remembering $(1-\delta)$ increases over repetitions $(1967$, p. 472) and trials $(1967$, p. 477$)$, again contrary to typical two-state learning. It should be recognized, therefore, that support for the finite-state interpretation of Type II $d^{\prime}$ in recall does not entail support for all features of Bernbach's model.

\section{EXPERIMENT 1}

This experiment had four aims: (1) To confirm a constant Type II $\mathrm{d}^{\prime}$ across recall trials on which average retention is increasing; (2) to discover whether the inclusion of intralist intrusions in the class of incorrect responses is responsible for this constant Type II d' (a derivation from Banks', 1971, argument that the strengths of correct and incorrect responses may covary); (3) to attempt to validate Bernbach's (1967) finite-state interpretation of such a constant Type II $d^{\prime}$, using backward learning curves constructed from confidence ratings; and, (4) to determine whether mnemonic devices contribute to the occurrence of finite-state learning as suggested by Clarke, Landsford, and Dallenbach (1960) and Polson, Restle, and Polson (1965).

\section{Method}

Subjects. Six volunteers from a first-year psychology course served as subjects in order to gain course credit. There were three males in the rote group, and one male and two females in the mnemonic group.

Materials. Subjects were tested on 50 paired associates consisting of nouns sampled from the Paivio, Yuille, and Madigan (1968) norms so that they were high on concreteness $(C \geqslant 5)$, imagery $(I \geqslant 5)$, meaningfulness $(m \geqslant 6)$, and frequency ( $F>10 /$ million). These words were paired randomly, but with obvious associations excluded, and the pairs mounted on slides for screen presentation.

Procedure. Subjects were tested in one group, but were given copies of either rote or mnemonic instructions in written form. Mnemonic subjects were required to associate the pairs of nouns by connecting them with a verb, while rote subjects were instructed to associate the words by repeating them over and over to themselves. Each pair of nouns was projected for $5 \mathrm{sec}$ during the study phase (with the normal Kodak carousel change time between pairs), while the first noun of each pair was projected for $10 \mathrm{sec}$ during the test phase. Stimulus nouns were always presented in the same sequence during both the study and test phases of a study-test cycle. Thus the procedure involved elements of both serial and paired associate learning. During the test phase, subjects were required to write a response and to rate on a 6-point scale (Murdock, 1966) how confident they were that the response was correct. The study-test cycle was repeated for a total of six trials. After the experiment was completed, subjects were asked whether they had kept to their instructed strategy or whether they had changed strategies during the experiment. No subject admitted to changing strategy.

\section{Results and Discussion}

Subjects' responses were classified into three groups: correct, extralist intrusions, and intralist intrusions. A 2 by 6 analysis of variance on correct responses revealed a nonsignificant rote-mnemonic effect $[F(1,4)=7.38]$, a significant trials effect $[F(5,20)=119.20, p<.001]$, and a significant interaction $[F(5,20)=5.89, p<.01]$. As can be seen from Figure 1, the trials effect reflected a typical progressive increase in performance over trials, while the interaction was due to faster acquisition for the mnemonic subjects. A similar analysis of mean confidence ratings resulted in significant groups $[F(1,4)=11.83, p<.05]$, trials 


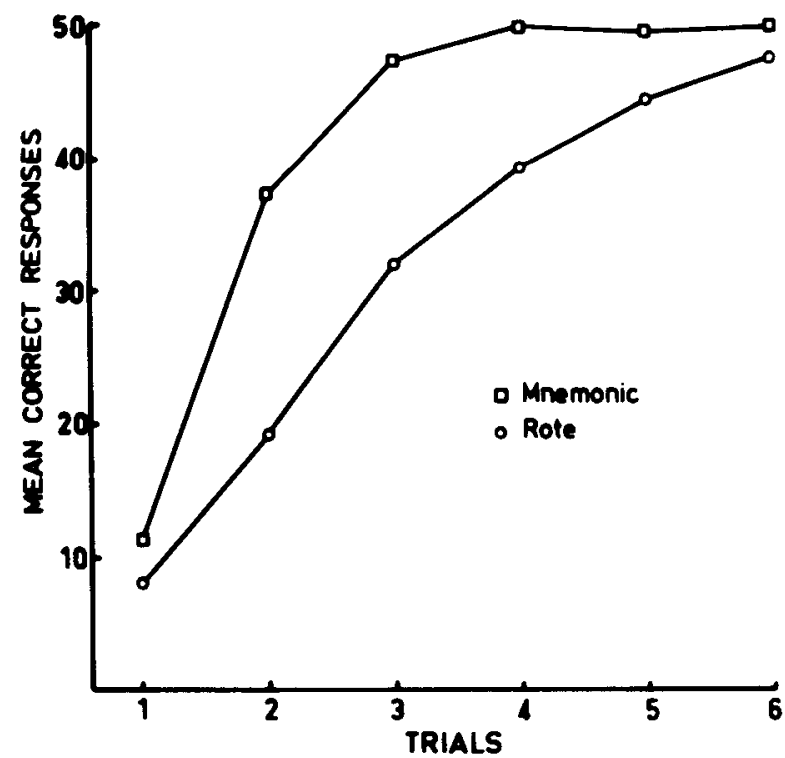

Figure 1. Mean number of correct responses over trials for rote and mnemonic subjects: Experiment 1.

$[F(5,20)=70.55, p<.001]$, and interaction effects $[F(5,20)=4.12, p<.01]$. Again there was a progressive performance increase over trials and the mnemonic subjects showed faster acquisition.

Both individual and group MOCs were constructed for rote and mnemonic groups on Trials 1 and 2 only, because on subsequent trials subjects recalled so many words correctly that is was impossible to construct reliable MOCs. Individual MOCs were obtained from 2 by 3 data matrices representing response class by confidence category, the three confidence categories being obtained from the original six by combining pairs of adjacent categories. Group MOCs were derived from data pooled over subjects in 2 by 6 matrices. Two sets of MOCs were calculated, indicating ability to discriminate: (1) correct responses from extralist intrusions and (2) intralist intrusions from extralist intrusions. Area under the MOC, P(A), was used as the discriminability measure, and this was normalized by a $2 / \pi$ arcsin $\sqrt{\mathrm{P}(\mathrm{A})}$ transformation (McNicol, 1972). These transformed areas can assume values between

Table 1

Mean Discriminability of Responses $[2 / \pi \arcsin \sqrt{\mathrm{P}(\mathrm{A})}]$ on Trials 1 and 2: Experiment 1

\begin{tabular}{llcccc}
\hline & & \multicolumn{3}{c}{$\begin{array}{c}\text { Discriminability from } \\
\text { Extralist Intrusions }\end{array}$} \\
\cline { 3 - 6 } Learning & & $\begin{array}{c}\text { Correct } \\
\text { Responses }\end{array}$ & \multicolumn{1}{c}{$\begin{array}{c}\text { Intralist } \\
\text { Intrusions }\end{array}$} \\
\cline { 3 - 7 } Strategy & Index & Trial 1 & Trial 2 & Trial 1 & Trial 2 \\
\hline \multirow{2}{*}{ Rote } & Individual & .86 & .86 & .55 & .56 \\
& Group & .88 & .90 & .58 & .56 \\
Mnemonic & Individual & .97 & .92 & .58 & .60 \\
& Group & 1.00 & .97 & .59 & .60 \\
\hline
\end{tabular}

0 and 1 , with .5 representing chance performance. In conformity with Banks' (1970, p. 91) recommendation, $P(A)$ was used instead of $d^{\prime}$ because it takes all points of a MOC into account while not requiring any assumptions about the form of the underlying distributions. The $\mathrm{P}(\mathrm{A})$ values were not corrected for guessing because the guessing probability was close to zero in the present experiment.

Table 1 shows these discriminability indices for both groups of subjects on Trials 1 and 2 . There is close agreement between the pooled and individual data despite substantial reasons for expecting otherwise (Hintzman, 1972). Statistical analyses of individual data for the discrimination of correct recalls from extralist errors revealed no significant effects for groups $[F(1,4)=6.78, p>.05]$, trials $[F(1,4)<1]$, or the interaction between them $[F(1,4)<1]$. This stability of Type II sensitivity over trials on which there were significant increases in the number of correct responses [for rote subjects, $t(24)=2.68, p<.05$; for mnemonic subjects, $t(24)=6.23, p<.001]$ cannot be attributed to the inclusion of intralist intrusions in the error set. This therefore eliminates a major potential source of positive covariation between correct and incorrect responses were learning to be continuously distributed (Banks, 1971).

The finite-state interpretation of the stable Type II sensitivity index is reinforced by backward rating curves (Figure 2) constructed for the rote and mnemonic subjects using Teghtsoonian and Teghtsoonian's (1972) method. Because there were so few errors after the

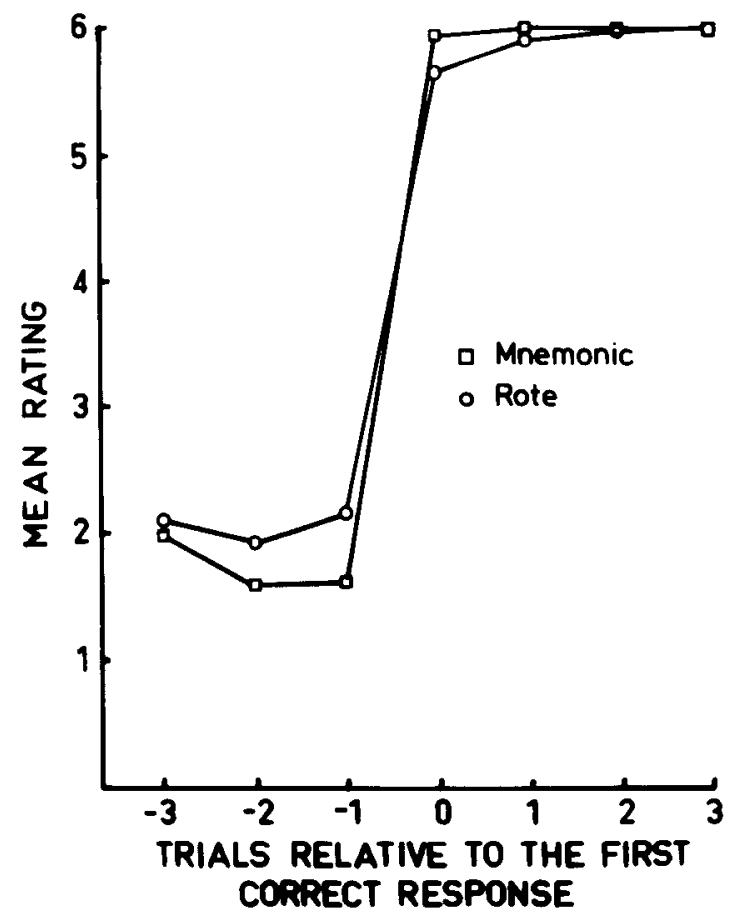

Figure 2. Backward rating curves for rote and mnemonic subjects: Experiment 1. 
first correct response (14 in all), they are not shown in the figure. The backward rating curves are in sharp contrast to the conventional trials data (Figure 1) and clearly indicate a marked discontinuity in rating performance. Since recall was forced, and since the probability of a correct response prior to the last error was almost zero and stationary across the Vincentized first and second halves (.04), a two-state interpretation of the backward rating curves is clearly favored over Banks' (1970) initial argument that learning may be continuous yet subjects recall what they can and give these responses high ratings, then guess and give the guesses low ratings. Furthermore, the backward rating curves indicate that the finite-state effect is not dependent on the type of encoding strategy used by the subjects. Both rote and mnemonic subjects yielded functions consistent with Bernbach's (1967) model, whereas it might have been expected that rote subjects would show incremental learning.

There were no significant group, trial, or interaction effects with intralist vs. extralist intrusions [all $\left.F_{s}(1,4)<1\right]$. Of interest, however, is the fact that mnemonic subjects seem to have had partial knowledge when they gave an intralist intrusion: The discrimina. bilities of intralist from extralist intrusions were significantly above chance level on both trials for these subjects [a transformed $\mathrm{P}(\mathrm{A})$ of .58 is significantly different from chance at the .05 one-tailed level using $t(8)$ as the test distribution with a conservative error term pooled between and within subjects]. This is not in accord with Bernbach's (1967) one-stage model, but instead seems to imply a response learning stage as hypothesized by Underwood and Schulz (1960). However, the low level of discriminability involved suggests that this stage may be a comparatively trivial one that a finite-state model could neglect and still yield reasonable predictions.

\section{EXPERIMENT 2}

Luce's (1959) choice theory has been used in the analysis of several perception experiments (Broadbent, 1967; Broadbent \& Gregory, 1967; Morton, 1969) and has also been applied to paired associate recall (Ingleby, 1968; McNicol \& Ryder, 1971). Choice theory yields a discriminability index, $\alpha$, analogous to $d^{\prime}$ of SDT, but has an advantage over SDT in that it can be easily applied to experimental situations where responses are open ended, provided the stimuli and responses can be assigned uniquely to two or more classes of known relative size. In a recall experiment, $\alpha$ reflects the subject's ability to discriminate correct responses in a particular class from incorrect responses in that class. Thus $\alpha$ is analogous to Type II $\mathrm{d}^{\prime}$ because it measures the discriminability of responses rather than the discriminability of stimuli. However, since a subject's response evaluations (ratings) are not used in calculating $\alpha$, it may not behave like a standard Type II index (Healy \& Jones, 1973). Experiment 2 aimed to study this issue as well as to replicate the effects found in Experiment 1.

\section{Method}

Subjects. Six female students from a first-year psychology course volunteered to serve as subjects in order to gain course credit. One subject omitted responses to such an extent that she was excluded from all analyses with the exception of the choice theory analysis. Ingleby (1968) has shown that the omission of responses has little effect on choice theory indices.

Materials. Fifty paired associates were constructed from nouns in the Kucera and Francis (1967) word frequency count. Half of the pairs were made up of high-frequency words $(F>50)$ and half of low-frequency words $(\mathrm{F}<50)$. None of the words were hyphenated, compound, or of a language other than English.

Procedure. The procedure for presenting stimuli and recording responses was the same as in Experiment 1. After the experiment was completed, subjects were again shown each of the pairs and were asked to indicate which of the following strategies they used to learn the particular pair: (1) used a mental picture; (2) related the words to other words, constructed a phrase or sentence using the words, and other such strategies; (3) repeated the pair over and over. This procedure meant that learning strategy was a within- rather than between-subjects variable as in Experiment 1 , and different numbers of items were grouped under each strategy for each subject.

\section{Results and Discussion}

Subjects' responses were classified as either correct, extralist intrusions, or intralist intrusions.

Figure 3 shows the probability of a correct response over trials as a function of learning strategy. A 3 by 6 analysis of variance revealed a significant learning strategies effect $[F(2,8)=6.02, p<.05]$, a significant increase in learning over trials $[F(5,20)=41.11, p<.001]$, and a significant interaction $[F(10,40)=4.65, p<.001]$. A

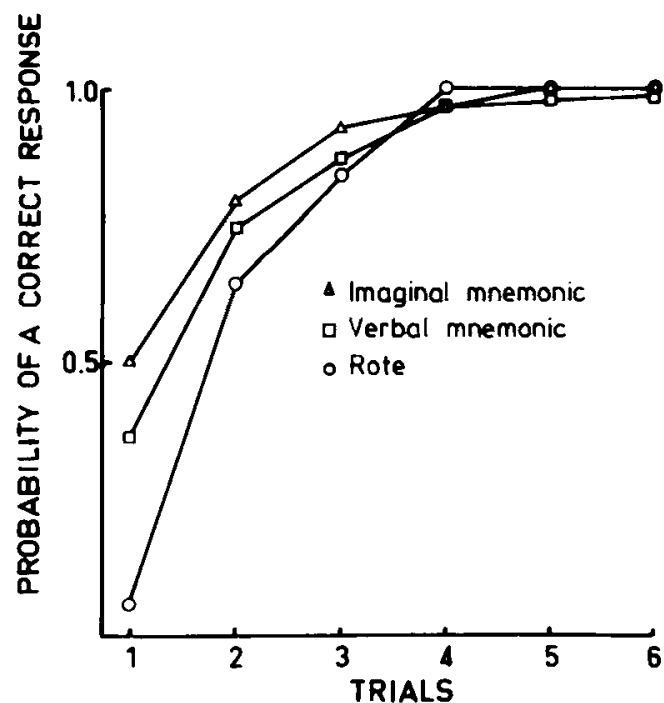

Figure 3. Probability of a correct response over trials for paired associates learned by rote and with imaginal and verbal mnemonics: Experiment 2. 


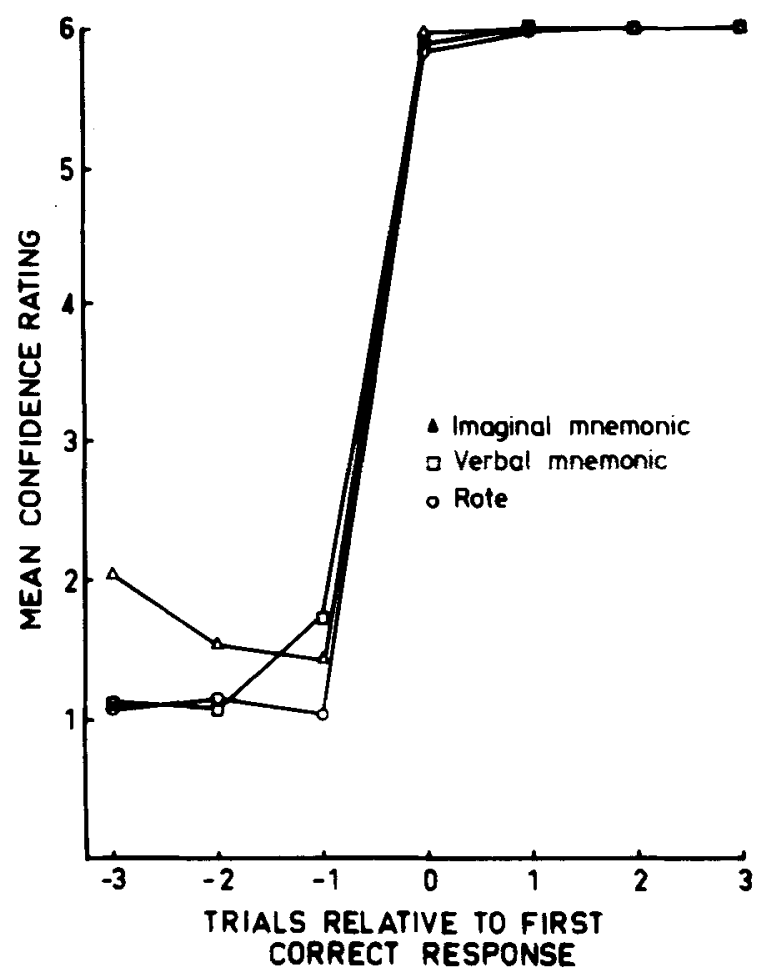

Figure 4. Backward rating curves for paired associates learned by rote and with imaginal and verbal mnemonics: Experiment 2 .

similar analysis of mean confidence ratings (where the subject's score was his mean confidence per strategy per trial) also resulted in significant learning strategies $[F(2,8)=12.48, \quad p<.001]$, trials $[F(5,20)=39.60$, $\mathrm{p}<.001]$, and interaction effects $[\mathrm{F}(10,40)=4.59$, $\mathrm{p}<.001]$.

Backward rating curves were constructed for each of the three learning strategies and are shown in Figure 4. Again, errors after the first correct are not shown because too few occurred (three in all, summing over all subjects and categories). Each of these curves clearly indicates finite-state processes, and this interpretation is supported by the virtually zero probability of a correct response prior to the last error.

Individual and group MOCs were constructed for the discriminability of correct responses from extralist intrusions by pooling over strategies to yield sufficient observations per cell. Again, only the first two trials could be considered because there were too few errors subsequently. Likewise, only group MOCs could be constructed for intralist vs. extralist intrusions on the first two trials because there were too few intralist errors for individual analyses. Table 2 gives $2 / \pi \arcsin \sqrt{\mathrm{P}(\mathrm{A})}$ values for the first two learning trials. The discriminability of correct responses from extralist intrusions remained constant over the two trials $[F(1,4)=1.029, p>.05]$, despite a significant change in the number of correct recalls $[\mathrm{t}(20)=7.01, \mathrm{p}<.001]$. The discriminability of intralist from extralist intrusions was minimal, casting some doubt on the existence of a response learning stage as was suggested on the basis of the results from Experiment 1.

The formulae given by McNicol (1972) were used to calculate $\alpha^{*}$ values for the frequent and infrequent paired associates. As $\alpha^{*}$ for frequent words requires as a coefficient an estimate of the ratio of frequent to infrequent words in the language, an initial collection of approximately 1,200 words was obtained from the Kucera and Francis (1967) word count by sampling every tenth page. Twenty-three of these words met the criteria for inclusion as frequent words, while 171 met the criteria for infrequent words, yielding a weighting of .1345 for frequent words.

Since $\alpha^{*}$ can only be calculated when there is at least one entry in each cell of the stimulus-response matrix, a requirement not met in some instances, a 1 was added to each cell of the matrix to permit statistical evaluation. Means for these corrected values (normalized by a $\log _{10}$ transformation) as well as means of uncorrected values for samples of varying size are shown in Table 3 for the first three learning trials.

A 2 by 3 analysis of variance on the transformed corrected values revealed a significant difference between frequent and infrequent words $[F(1,5)=62.65$, $p<.001]$, as well as a significant increase over trials $[F(2,10)=46.20, \quad p<.001]$, but no significant interaction.

There appear to be two anomalies with these results. First, although $\log \alpha^{*}$ was higher for infrequent than for frequent words, there was no significant difference between the two sets of words in number correct $[F(1,5)=1.37]$. This may of course be taken to indicate

Table 2

Mean Discriminability of Responses $[2 / \pi \arcsin \sqrt{\mathrm{P}(\mathrm{A})}]$ on Trials 1 and 2: Experiment 2

\begin{tabular}{|c|c|c|c|}
\hline \multirow{2}{*}{$\begin{array}{l}\text { Discriminability from } \\
\text { Extralist Intrusions }\end{array}$} & \multirow[b]{2}{*}{ Index } & \multicolumn{2}{|c|}{ Trial } \\
\hline & & 1 & 2 \\
\hline Correct Responses & $\begin{array}{l}\text { Individual } \\
\text { Group }\end{array}$ & $\begin{array}{l}.88 \\
.89\end{array}$ & $\begin{array}{l}.95 \\
.95\end{array}$ \\
\hline Intralist Intrusions & Group & .58 & .51 \\
\hline
\end{tabular}

Note-Individual MOCs could not be determined for discriminability of intralist from extralist intrusions due to insufficient intralist intrusions.

Table 3

Mean $\log \alpha^{*}$ on Trials 1-3: Experiment 2

\begin{tabular}{|c|c|c|c|c|}
\hline \multirow[b]{2}{*}{ Words } & \multirow[b]{2}{*}{ Index } & \multicolumn{3}{|c|}{ Trial } \\
\hline & & 1 & 2 & 3 \\
\hline Frequent & $\begin{array}{l}\text { Corrected } \\
\text { Uncorrected }\end{array}$ & $\begin{array}{l}-.81 \\
-1.01(5)\end{array}$ & $\begin{array}{l}-.15 \\
-.15(5)\end{array}$ & $\begin{array}{l}.19 \\
.21(4)\end{array}$ \\
\hline Infrequent & $\begin{array}{l}\text { Corrected } \\
\text { Uncorrected }\end{array}$ & $\begin{array}{l}.12 \\
.15(6)\end{array}$ & $\begin{array}{l}.93 \\
.89(4)\end{array}$ & $\begin{array}{l}1.19 \\
.88(2)\end{array}$ \\
\hline
\end{tabular}

Note-The numbers in parentheses indicate the number of observations upon which the mean is based. 
that number correct is confounded by response bias and, therefore, does not properly reflect sensitivity for each class. On the other hand, the result may be due to an artifact resulting from the inverse relationship between bias and sensitivity in the present data. Although $\alpha^{*}$ was larger for infrequent than frequent words, bias $(v)$ was toward frequent words [ $v$ values for frequent and infrequent words were all greater than one for all subjects over the three trials, and all mean $\log v$ values likewise differed significantly $(p<.001)$ from zero using two-tailed $t(10)$ as the test distribution]. According to McNicol (1972), "if there is a significant bias to one class and it is also found that $\alpha$ for that class is significantly lower than for the other class, then the difference in sensitivity cannot be trusted" (p. 152). It should be noted, however, that this interpretation rests on Ingleby's (1968) use of $d^{\prime}$ and $\beta$ from SDT as the benchmarks for $\alpha$ and $v$ in computer simulations of recognition performance. This of course presumes that SDT provides the proper solutions to which Luce (1959) values are approximations. It is of note that Ingleby (1973) did not regard his similar results with cued recall of English surnames as artifactual, although he did consider the possibility.

There is one difficulty, however, that may invalidate the choice theory indices. Whereas $\alpha^{*}$ shows marked increases over trials, the SDT index remains constant, a result supported by the finite-state processes revealed in the backward rating curves. The increase in $\alpha^{*}$ over trials cannot be explained as being due artifactually to related changes in response bias because response bias did not significantly change over trials $[v$ for both frequent and infrequent words yielded $F(2,10)<1]$.

Choice theory may give these apparently anomalous results because it is based on the assumption that learning is incremental. In Ingleby's (1968) application of choice theory to recall, it is assumed that all paired associates within a particular class have continuously distributed strength values, with the increment in strength resulting from some memory variable being $\alpha$ for that class. If, however, a finite-state theory is correct, as the evidence presented in this article suggests, $\alpha$ becomes an index of the number of items in the learned state (since it is calculated by dividing the number of items in the learned state by the number of items in the unlearned state), rather than an index of relative strength. As such, it is not a Type II index, even though it purports to measure the discriminability of correct and erroneous responses within a class. The nature of the Type II MOC in recall reveals why this should be so. The cumulative distributions of correct recall and error frequencies across rating categories are converted to hit and false alarm rates by expressing them as proportions of the totals for correct and erroneous recalls, respectively. The Type II MOC is thus not directly influenced by the number of correct and incorrect recalls, but is sensitive instead to changes in the probability distributions across the rating categories. In contrast, $\alpha$ very clearly is directly affected by the number of correct recalls, and thus is not an appropriate index of sensitivity when recall is subject to finite memory states.

\section{GENERAL DISCUSSION}

The results of both experiments indicate that paired associate recall is a finite-state process and therefore support Bernbach's (1967) interpretation of the constancy of Type II $d^{\prime}$ in recall. There is no support, however, for the details of Bernbach's remembering model: Once learned, an item was rarely forgotten, and neither the probability of learning nor of forgetting was dependent on number of trials.

In contrast to the present findings, Hintzman (1972) has reported data that support an incremental theory. He analyzed recall data by examining discriminability and mean confidence rating for items recalled correctly on different numbers of trials. Both of these measures exhibited increases over trials. Since Hintzman's method of analysis was in some ways similar to the present backward rating curve analysis, the discrepancy in results requires explanation.

One critical difference between the two methods of analysis is that, whereas Hintzman (1972) compared groups of items that differed in the number of trials on which they had been correctly recalled prior to a given trial, the backward rating curves compared items indifferently to the number of times they had been correctly recalled. Bernbach (1972) accounted for Hintzman's results by suggesting that items high on the decision scale are learned fastest. The set of items that has been correct several times in a row will thus have a mean scale location higher than that for items correct for a lesser number of trials. However, the backward rating curve analysis cannot be criticized in the same way because it is comparing items with themselves at different points during learning and therefore is not subject to such item selection biases.

Bernbach (1972), however, went on to be scathing of all uses of mean confidence rating: "Mean confidence rating is a worthless summary statistic in any instance except one in which it is absolutely certain that there is no taint of criterion change, a rare situation indeed" (p. 537). Supporters of an incremental model might argue, therefore, that the present results are due to a criterion shift. Although this may be partly justified, it is difficult to see how an incremental model could appeal to a criterion shift to account for the very marked discontinuity in rating shown by the backward rating curves. The first correct response should not be differentiated from the previous incorrect one to such an extent as to provide a basis for a subject to shift his rating criterion so markedly. Moreover, despite the near zero evocation criterion induced by forced 
responding, there was no evidence of an increase in the probability of a correct response prior to the last error.

Nevertheless, backward rating curves deserve crossvalidation from still further indicators of finite-space processes before their use can be uncritically accepted. There are several possible methods that could be used for this purpose. One would be to use Estes' (1964) second-guess procedure to detect partial learning on trials before the first correct response. The problem with Estes' method is that it only detects increments in memory strength on trials before the first correct response, whereas Hintzman's (1972) data showed increments after the first correct response. The backward rating procedure might therefore be more appropriately validated by the use of other indices of memory strength, such as response latency (Millward, 1964) and the galvanic skin response component of the orienting response (Kintsch, 1965), which can detect increases in memory strength both before and after the first correct response. However, it could be argued that even these indices are affected by criterion shifts as well as by changes in memory strength.

\section{REFERENCES}

Anderson, J. R., \& Bower, G. H. A propositional theory of recognition memory. Memory \& Cognition. 1974, 2. 406-412.

Banks, W. P. Signal detection theory and human memory. Psychological Bulletin, 1970, 74, 81.99.

Banks, W. P. Confidence-rated recall, $d_{r}$, and tests of Bernbach's finite-state theory in recall. Psychological Bulletin, 1971, 76, 151-152.

Bernanch, H. A. Decision processes in memory. Psychological Revien, 1967, 74, 462-480.

BERnBACH, H. A. Invariance of $\mathrm{d}^{*}$ in memory: Response to Banks. Psychological Bulletin, 1971, 76. 149-150. (a)

BernaACH, H. A. Strength theory and confidence ratings in recall. Psychological Review. 1971, 78, 338-340. (b)

BernaAch, H. A. Confidence ratings for individual items in recall. Psychological Review, 1972, 79, 536-537.

Broadbent, D. E. Word-frequency effect and response bias. Psychological Review. 1967, 74, 1-15.

Broadbent, D. E., \& Gregory, M. Perception of emotionally toned words. Nature, 1967, 215, 581-584.

Brown, J. (Ed.). Recall and recognition. New York: Wiley, 1976.

Clarke, F. R. Confidence ratings, second-choice responses and confusion matrices in intelligibility test. Journal of the Acoustical Society of A merica, 1960, 32, 35-46.

Clarke, L. L.. Landsford, T. G., \& Dallentach, K. M. Repetition and associative learning. American Journal of Psychology, 1960, 73, 22-40.

Estes, W. K. All-or-none processes in learning and retention. American Psychologist. 1964. 19. 16-25.
Healy, A. F., \& Jones, C. Criterion shifts in recall. Psychological Bulletin, 1973, 79, 335-340.

Hintzman, D. L. Confidence ratings in recall: A reanalysis. Psychological Review, 1972, 79, 531-535.

INGLEBY, J. D. Decision-making processes in human perception and memory. Unpublished doctoral dissertation, Cambridge University, 1968.

INGLEBY, J. D. A test of current explanations of the effect of item familiarity on memory. Quarterly Journal of Experimental Psychology, 1973, 25, 378-386.

Kintsch, W. Habituation of the GSR component of the orienting reflex during paired-associate learning before and after learning has taken place. Journal of Mathematical Psychology, 1965, 2, 330-341.

KINTSCH, W. The representation of meaning in memory. Potomac, Md: Lawrence Erlbaum, 1974.

KuĆera, H., \& Francis, W. N. Computational analysis of present-day American English. Providence: Brown University Press, 1967.

Lecoce, P.. \& Tiberghien, G. Rappel et reconnaissance: Hypothèses monistes. Année Psychologique, 1973, 73, $635-680$.

LUCE, R. D. Individual choice behavior. New York: Wiley, 1959.

McNicol, D. A primer of signal detection theory. London: Allen \& Unwin, 1972.

MCNicol, D.. \& RYDER, L. A. Sensitivity and response bias effects in the learning of familiar and unfamiliar associations by rote or with a mnemonic. Joumal of Experimental Psychology, 1971, 90, 81-89.

Millw ARD, R. Latency in a modified paired-associate learning experiment. Journal of Verbal Learning and Verbal Behavior, 1964, 3, 309-316.

Morton, J. Interaction of information in word recognition. Psychological Review, 1969, 70, 165-178.

Murdock, B. B. The criterion problem in short-term memory. Journal of Experimental Psychology, 1966, 72, 317-324.

Paivio, A., Yuille, J. C., \& Madigan, S. A. Concreteness, imagery, and meaningfulness values for 925 nouns. Journal of Experimental Psychology Monograph, 1968, 76(1, Part 2).

Polson, M. C.. Restle, F., \& Polson, P. G. Association and discrimination in paired-associates learning. Journal of Experimental Psychology, 1965, 69, 47-55.

Suppes, P., \& Ginsberg, R. A. A fundamental property of all-or-none models, binomial distribution of responses prior to conditioning, with application to concept formation in children. Psychological Review, 1963, 70, 139.161.

Teghtsoonian, R., \& Teghtsoonian, M. Further evidence of discontinuity in learning to recognize. Journal of Verbal Leaming and Verbal Behavior, 1972, 11, 212-220.

Tulving. E. Ecphoric processes in recall and recognition. In J. Brown (Ed.), Recall and recognition. New York: Wiley, 1976.

UNDERWOOD, B. J., \& SChulz, R. W. Meaningfulness and verbal learning. Philadelphia: Lippincott, 1960.

(Received for publication November 22, 1977; revision accepted November 30,1977 .) 